\title{
New Insights into Translational Regulation in the Endoplasmic Reticulum Unfolded Protein Response
}

\author{
Graham D. Pavitt ${ }^{1}$ and David Ron ${ }^{2}$ \\ ${ }^{1}$ Faculty of Life Sciences, University of Manchester, Oxford Road, Manchester M13 9PT, \\ United Kingdom \\ ${ }^{2}$ Metabolic Research Laboratories, University of Cambridge, Addenbrookes Hospital, Hills Road, \\ Cambridge CB2 0QQ, United Kingdom \\ Correspondence: graham.pavitt@manchester.ac.uk and dr360@medschl.cam.ac.uk
}

\begin{abstract}
Homeostasis of the protein-folding environment in the endoplasmic reticulum (ER) is maintained by signal transduction pathways that collectively constitute an unfolded protein response (UPR). These affect bulk protein synthesis and thereby the levels of ER stress, but also culminate in regulated expression of specific mRNAs, such as that encoding the transcription factor ATF4. Mechanisms linking eukaryotic initiation factor 2 (elF2) phosphorylation to control of unfolded protein load in the ER were elucidated more than 10 years ago, but recent work has highlighted the diversity of processes that impinge on elF2 activity and revealed that there are multiple mechanisms by which changes in elF2 activity can modulate the translation of individual mRNAs. In addition, the potential for affecting this step of translation initiation pharmacologically is becoming clearer. Furthermore, it is now clear that another strand of the UPR, controlled by the endoribonuclease inositol-requiring enzyme 1 (IRE1), also affects rates of protein synthesis in stressed cells and that its effector function, mediated by the transcription factor X-box-binding protein 1 (XBP1), is subject to important mRNA-specific translational regulation. These new insights into the convergence of translational control and the UPR will be reviewed here.
\end{abstract}

In eukaryotes the early steps in biosynthesis of secreted proteins take place in the lumen of the endoplasmic reticulum (ER). Proteins are translocated cotranslationally in an unfolded state into the organelle, where a host of chaperones and enzymes assist in posttranslational modification and folding of the nascent chain of these ER client proteins. The flux of client proteins through the ER is subject to physiological regulation and can vary by up to an order of magnitude over a short period of time (Itoh and Okamoto 1980). These brisk fluctuations in the load of ER client proteins, which are all the more conspicuous in the specialized secretory cells of complex animals, has favored the evolution of homeostatic signaling pathways

Editors: John W.B. Hershey, Nahum Sonenberg, and Michael B. Mathews

Additional Perspectives on Protein Synthesis and Translational Control available at www.cshperspectives.org

Copyright (C) 2012 Cold Spring Harbor Laboratory Press; all rights reserved; doi: 10.1101/cshperspect.a012278

Cite this article as Cold Spring Harb Perspect Biol 2012;4:a012278 
that couple the capacity of the ER to the load facing it. These pathways constitute an unfolded protein response (UPR) whose molecular details were first worked out in yeast (Ron and Walter 2007). The yeast UPR is a transcriptional response, by which cells up-regulate expression of ER chaperones in response to the threat of protein misfolding in the ER lumen. In higher eukaryotes the transcriptional response is complemented by feedback from the lumen of the ER to the translational apparatus to attenuate the flux of client proteins into the organelle (Fig. 1).

The eukaryotic initiation factor $2 \alpha(\mathrm{eIF} 2 \alpha)$ kinase PERK (RNA-dependent protein kinaselike ER kinase) is the key mediator of the translation arm of the UPR, and eIF $2 \alpha$ phosphorylation has emerged as an evolutionarily conserved node for regulating bulk protein synthesis and for affecting mRNA-specific changes in rates of translation. The molecular mechanisms affecting eIF $2 \alpha$ phosphorylation's role in regulating the initiation step of mRNA translation have been well characterized and were subject to extensive review (Ron and Harding 2007). Here we will focus on new developments in this area. The discovery of a role for eIF5 as a antagonist of guanine nucleotide exchange by the eIF2B complex (Jennings and Pavitt 2010), working alongside eIF2 $\alpha$ phosphorylation to restrain the re-cycling of eIF2 and thereby rates of translation initiation, will be highlighted. The development of genomic tools for profiling the disposition of ribosomes on mRNAs in vivo has provided new insight into how eIF $2 \alpha$ phosphorylation regulates the rate of translation

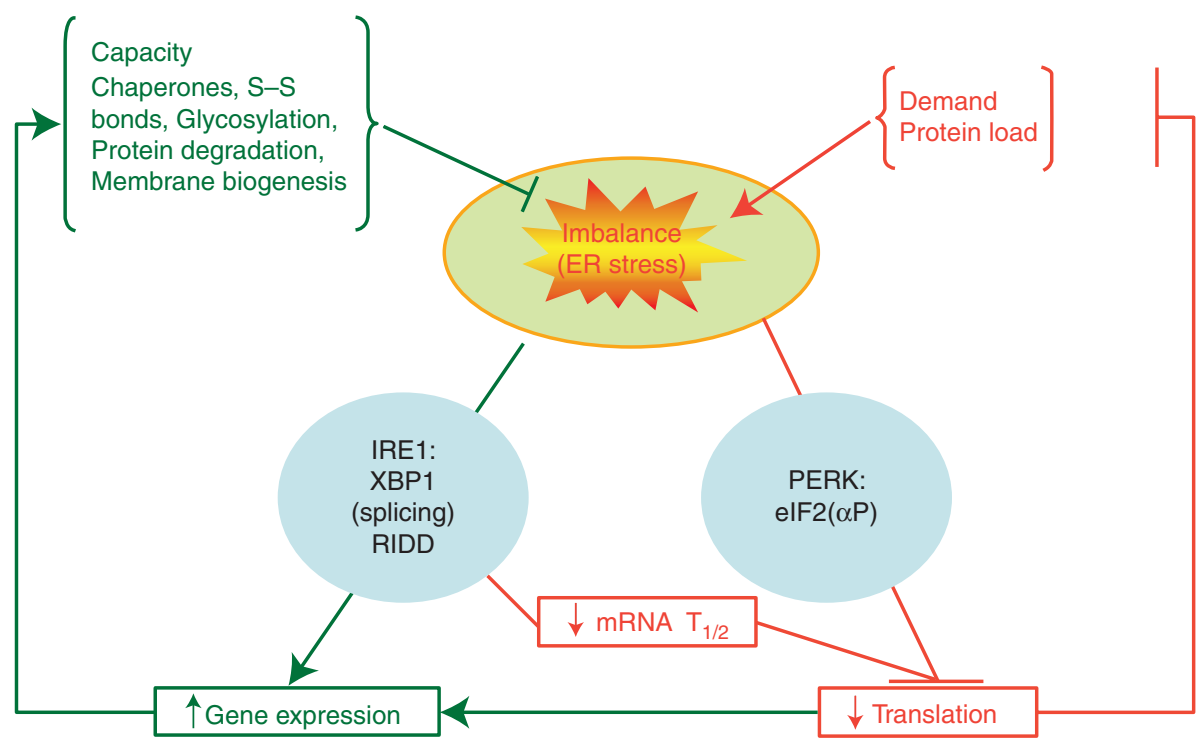

Figure 1. Overview of the unfolded protein response. Fluctuations in the unfolded protein load placed on the endoplasmic reticulum can give rise to transient imbalance between capacity and demand, which we refer to as ER stress. This elicits two major adaptations: attenuation of new protein synthesis (mediated by PERK and eIF $2 \alpha$ phosphorylation), which rapidly decreases the load on the organelle; and induction of a gene expression program (effected by IRE1-mediated XBP1 splicing) that up-regulates the organelle's capacity to deal with incoming proteins. Regulated translation is also coupled to changes in gene expression, as indicated by the horizontal arrow connecting the two outputs. Destabilization of mRNAs encoding secreted proteins by regulated IRE1-dependent degradation (RIDD) contributes to the relief of ER load. Because these adaptations can be elicited experimentally by manipulations that perturb protein folding in the ER, they came to be known as the ER unfolded protein response (UPR). For simplicity, the third mediator of the UPR, ATF6, is omitted from this diagram. 
Translational Regulation in the UPR

initiation (Ingolia et al. 2009). The significance of these developments to our understanding of the physiological importance of eIF $2 \alpha$ phosphorylation will be covered in detail.

Regulating the rate of global protein synthesis and with it the level of ER stress in cells has proven to be an important influence on cellular life/death decisions. The lessons provided from knockout of the eIF2 $(\alpha \mathrm{P})$-directed phosphatases will be reviewed. As pharmacological control of eIF2 $(\alpha \mathrm{P})$ dephosphorylation has emerged as a potentially important way to bias life/death decisions; the implications of research in that area too will be highlighted.

The ancient and conserved transcriptional pathway of the UPR is mediated by the transmembrane ER protein inositol-requiring enzyme 1 (IRE1), which is activated in response to unfolded protein stress in the ER (Cox et al. 1993; Mori et al. 1993). Activated IRE1 is a sequence-specific endoribonuclease that participates in an unconventional cytoplasmic mRNA splicing event that culminates in the expression of a transcription factor, Haclp in yeast and X-box-binding protein 1 (XBP1) in animals (Cox and Walter 1996; Yoshida et al. 2001; Calfon et al. 2002). Although the basic mechanisms underlying this unusual signal transduction pathway were worked out more than 10 years ago, recent studies have brought to light novel aspects of translational control that set up the XBP1 mRNA for IRE1-mediated splicing in mammalian cells. This remarkable example of mRNA-specific translational regulation in eukaryotes will be reviewed here in detail.

Recent work has also called attention to an alternative mode for IRE1 activity with relaxed specificity for substrates. This activity, which is apparently unique to animal cell IRE1, results in promiscuous degradation of membrane-bound mRNA and affects the repertoire of proteins synthesized in ER-stressed cells (Hollien and Weissman 2006; Hollien et al. 2009). This recently characterized activity of IRE1 has an interesting relationship to that of RNase L, a component of the innate immune response that evolved from the ancestral IRE1 gene. Here we will review the significance of these newly discovered relationships.

\section{eIF5 IS CRITICAL FOR THE eIF2 $(\alpha \mathrm{P})$-MEDIATED TRANSLATIONAL CONTROL RESPONSE}

eIF2 is a $\mathrm{G}$ protein that cycles between an active form binding GTP and $\mathrm{tRNA}_{\mathrm{i}}^{\mathrm{Met}}$ (called the ternary complex or TC) and an inactive GDPbound state. It is this cycling that is interrupted by the PERK-mediated phosphorylation. The nucleotide status of eIF2 is controlled by two factors: eIF5 and eIF2B. It is well established that eIF2B is the guanine nucleotide exchange factor (GEF) that stimulates release of GDP (Rowlands et al. 1988; Nika et al. 2000), allowing GTP and $\mathrm{tRNA}_{\mathrm{i}}^{\mathrm{Met}}$ to bind eIF2, and that eIF5 is the GTPase-accelerating factor that stimulates GTP hydrolysis (Das et al. 2001; Paulin et al. 2001) at or before AUG codon recognition. However, it was suggested recently that (at least in yeast) eIF2-GDP/eIF5 are released from initiating ribosomes together following GTP hydrolysis, because an abundant complex containing these factors was identified (Singh et al. 2006). It was then shown that eIF5 has a second function as a GDP-dissociation inhibitor (GDI) that prevents premature dissociation of GDP from eIF2 (Jennings and Pavitt 2010), thus providing an additional step in the translation initiation process, one that antagonizes eIF2B-mediated nucleotide exchange.

eIF2B GEF activity is inhibited by eIF2 phosphorylation (Pavitt et al. 1998). eIF2B forms a more stable complex with $\operatorname{eIF} 2(\alpha \mathrm{P})$, but it is suggested that binding is altered such that nucleotide exchange is not favored. A range of mutations in yeast eIF2B subunits can suppress the effects of eIF2( $\alpha \mathrm{P})$ (Pavitt et al. 1997), and where tested, these reduced affinity for phosphorylated eIF2 $\alpha$ (Krishnamoorthy et al. 2001), preventing translational control. Similar effects were seen when equivalent mutations were introduced into mammalian eIF2B (Kimball et al. 1998) and were recently shown to enhance viral infection in a cell culture model in which the effects of eIF2B mutation were equivalent to knockdown of the relevant eIF $2 \alpha$ kinase (Elsby et al. 2011). As eIF2B is less abundant than eIF2, phosphorylation of only a fraction of the total eIF2 can have a significant impact on eIF2B 
activity and consequently significantly reduce the amounts of active eIF2 - GTP in affected cells.

It was found that eIF5 GDI is important to sensitize cells to eIF2 phosphorylation. In an experiment in which eIF $2 \alpha$ phosphorylation was artificially elevated by a constitutively active kinase, total translation and cell growth were impaired. Remarkably, growth was restored simply by a single GDI mutant form of eIF5 (bearing a change from a conserved tryptophan to phenylalanine) that destabilizes the eIF2/eIF5 complex and thereby eliminates GDI activity. Thus, in normal cells, eIF5 GDI function was necessary to sensitize cells appropriately to eIF2 phosphorylation. Whether eIF5 GDI function is conserved in mammalian cells is not yet clear, but the critical elements identified in yeast are conserved in mammals including man. The experiment outlined above suggests that for mediating the response to eIF2 $(\alpha \mathrm{P})$ it is the physical ability to form an eIF2-GDP/eIF5 complex that is the most critical step for involvement of eIF5 in eIF2 $(\alpha \mathrm{P})$ regulation. The significance of this finding to the UPR and eIF2 $(\alpha \mathrm{P})$ regulatory events other than amino acid starvation remains to be determined. However, the findings suggest that varying eIF2B and/or eIF5 levels/ activity in different cell types could modulate their sensitivity to this regulatory mechanism. This could help explain tissue-specific defects observed in animal models and human disease pathology associated with alterations to these factors.

A relevant example of tissue-specific pathology is the link between eIF2B mutations and a fatal brain disorder, vanishing white matter disease (VWM) or childhood ataxia with CNS hypomyelination $(\mathrm{CACH})$ (Pavitt and Proud 2009). VWM/CACH mutations cause celltype-specific pathology, primarily affecting glial cells (astrocytes and oligodendrocytes), although some patients also present with premature ovarian failure (Fogli et al. 2003) and severe eIF2B mutations affect multiple organs (van der Knaap et al. 2003). Heightened signaling in the eIF2 $(\alpha \mathrm{P})$-dependent branch of the UPR has been observed in oligodendroglial cell lines (Kantor et al. 2008) and brain samples of VWM/CACH (van Kollenburg et al. 2006).
eIF2B GEF activity is also impaired in immortalized lymphocytes from patients, but a parallel branch of the UPR, XBP1 splicing, is unaffected (Horzinski et al. 2009, 2010). In contrast, a heightened UPR but apparently normal GEF activity was found with assays of primary fibroblasts (Kantor et al. 2005). Although the molecular basis underlying the cell-type specificity of this disorder remains a mystery, the generation of a disease model eIF2B mutant mouse should facilitate more rapid progress in distinguishing causes from consequences (Geva et al. 2010).

\section{INDIVIDUAL mRNA TARGETS OF eIF2 $(\alpha \mathrm{P})$ CONTROL REVEAL DIVERSITY IN UORF- DEPENDENT REGULATION OF TRANSLATION INITIATION}

Phosphorylation of eIF2 reduces the level of eIF2 $\cdot G T P \cdot$ tRNA $_{i}^{\text {Met }}$ ternary complexes in cells, limiting its availability for translation initiation events. Although this reduces translation initiation rates for many mRNAs, it can also enhance translation of other mRNAs. One well-studied and important example is ATF4 mRNA, which has been reviewed previously (see, e.g., Ron and Harding 2007; Jackson et al. 2010). ATF4 is a transcription factor with multiple target genes that are transcriptionally activated by ER and other stresses that induce eIF2 phosphorylation. ATF4 translation increases with increasing eIF2 phosphorylation during stress and is dependent on eIF2 $\alpha$ kinase activation. Mouse PERK kinase-knockout embryonic stem cells fail to induce ATF4 translation in response to the ER stress agent thapsigargin, unlike wildtype cells similarly treated (Harding et al. 2000).

ATF4 is translationally controlled by a regulated reinitiation mechanism ( $\mathrm{Lu}$ et al. 2004; Vattem and Wek 2004). Its mRNA bears two upstream open reading frames (uORFs) in the $5^{\prime}$ leader sequence before the main coding ORF. These uORFs restrict the flow of translating ribosomes scanning from the $5^{\prime}$ mRNA cap to the ATF4 AUG initiation codon. The current model is based largely from reporter gene construct analyses and similarity to the well-documented model for regulated reinitiation on yeast GCN4 
Translational Regulation in the UPR

mRNA (see Fig. 2). It proposes that ribosomes scan from the $5^{\prime}$ cap and translate uORF1, which is only three codons in length. The $40 \mathrm{~S}$ subunit remains mRNA-associated following translation termination and resumes its migration downstream. Rapid acquisition of TC by the $40 \mathrm{~S}$ subunit enables scanning and reinitiation downstream at uORF2. Translation of this uORF prevents translation of the ATF4 ORF. During stress eIF2 $\alpha$ kinase activation lowers TC levels. Reinitiation appears more sensitive to a modest reduction in TC levels than primary initiation, delaying the reacquisition of TC following uORF1 translation. Thus a portion of the ribosomes scan past uORF2 AUG before reacquiring TC and are unable to initiate translation of this repressive uORF. Some of these $40 \mathrm{~S}$ ribosomes do acquire TC between the uORF2 AUG and ATF4 AUG and translate the ATF4 protein. A related gene, ATF5, has an almost identical regulated reinitiation translational control mechanism (Zhou et al. 2008). Reinitiation generally requires that the first uORF be short (Poyry et al. 2004). For reinitiation to be regulated by eIF2 $(\alpha \mathrm{P})$, uORF1 must be followed by a second uORF.

Alternative mechanisms for uORF-mediated regulation have been described for the UPR genes $C H O P$ (Palam et al. 2011) and GADD34 (Lee et al. 2009). Like ATF4 and ATF5, both CHOP and GADD34 mRNAs are transcriptionally induced following ER stress and require a translational control mechanism to ensure they are only translated for the duration of the stress response or period of elevated eIF2 phosphorylation. $\mathrm{CHOP}$ mRNA possesses a single $34-\mathrm{Co}-$ don uORF in its $5^{\prime}$ leader sequence that contains two in-frame AUG codons at positions 1 and 4 in the $\mathrm{UORF}$, both in poor recognition contexts. Reporter gene experiments showed that regulation is not dependent on the first AUG (uAUG1), but requires the second (uAUG2). The experimental findings support a regulated "leakyscanning model” (Palam et al. 2011). Under conditions with low eIF2 $(\alpha \mathrm{P})$, initiation at uAUG2 dominates, followed by termination and ribosome release so that CHOP translation is low, whereas when eIF $2(\alpha \mathrm{P})$ is high, a greater fraction of ribosomes bypass both uAUG1 and uAUG2 and instead initiate at the CHOPAUG, elevating $\mathrm{CHOP}$ expression. The sequence of the CHOP uORF (codons 24-34) was also found to be important under nonstress conditions: Translation of this element inhibits subsequent downstream initiation events. GADD34 translation may be operationally similar to the $C H O P$-regulated

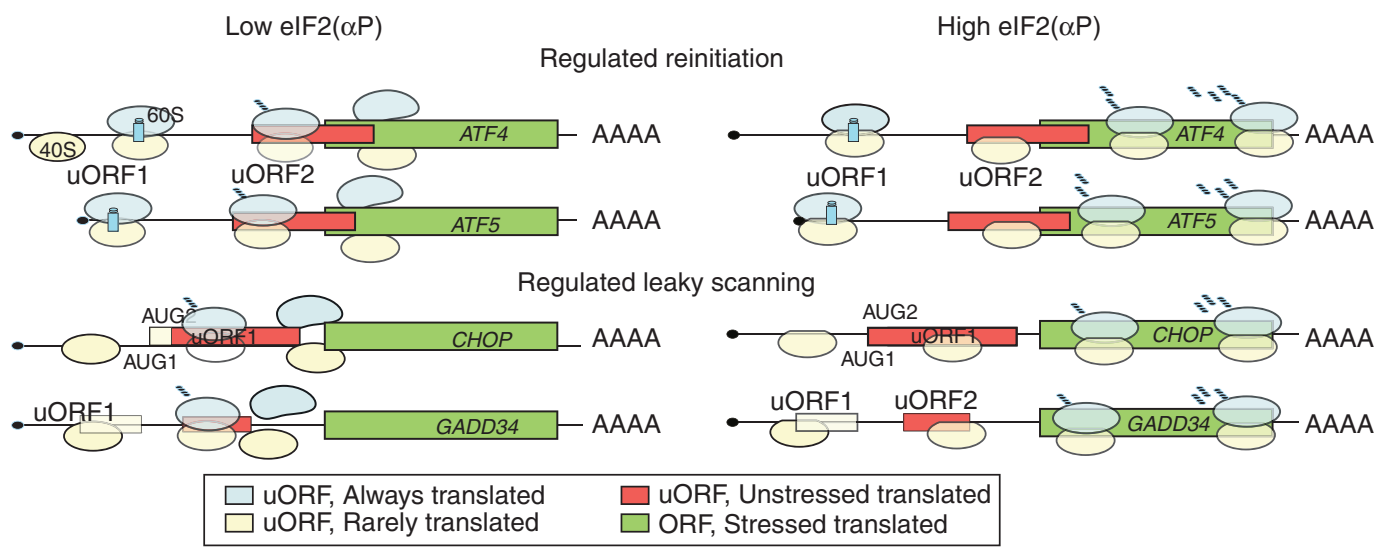

Figure 2. Translational control models for genes with uORFs translated during the UPR. Two states, normal conditions (left) and stress conditions with high eIF2 phosphorylation (right), are shown. Each mRNA is represented with the main coding ORF shown in green and uORFs with differing colors depending on whether they are always translated (cyan), translated in unstressed conditions only (red), or rarely translated (unfilled). Occupancy by scanning $40 \mathrm{~S}$ ribosomes (yellow) and translating $80 \mathrm{~S}$ (yellow and blue) is also indicated. See text for details. 
leaky-scanning mechanism, although GADD34 has two uORFs rather than a single uORF with two in-frame AUGs. Observations support a leaky-scanning model whereby in unstressed conditions most ribosomes scan through uORF1 and translate uORF2, whereas when $\operatorname{eIF} 2(\alpha \mathrm{P})$ is high, both uORFs are scanned through by a greater proportion of ribosomes and the GADD34 ORF is now translated (see Fig. 2) (Lee et al. 2009).

It is not yet clear how leaky scanning is regulated by levels of eIF2 $(\alpha \mathrm{P})$ : Does phosphorylated eIF2 confer altered AUG recognition directly, or are the activities of other translation factors modulated by $\operatorname{eIF} 2(\alpha \mathrm{P})$ ? In vitro experiments showed that eIF $2 \alpha$ could be cross-linked to the -3 position of a model mRNA just upstream of the AUG codon (where A $=+1$ ) (Pisarev et al. 2006). It is not clear if this interaction is modulated by eIF2 phosphorylation. Other factors/elements that may be involved are eIF1, eIF5, and $18 \mathrm{~S}$ rRNA. In yeast, mutations in eIFs $1,1 \mathrm{~A}, 2$, and 5 alter the ability of ribosomes to recognize non-AUG initiator codons (giving rise to yeast $\mathrm{Sui}^{-}$mutations) and also poor-context AUG codons (Martin-Marcos et al. 2011), although it is not yet clear what role these factors play in eIF2 $(\alpha \mathrm{P})$-modulated leaky scanning, or why multiple mechanisms have evolved to regulate translation by eIF $2(\alpha \mathrm{P})$.

Thus, these four genes reveal at least two alternate mechanisms for translational control of their expression. All are also transcriptionally controlled, with stress increasing mRNA levels several-fold for each gene. What are the benefits of combining two levels of control? It was suggested that the special architecture of the $5^{\prime}$ untranslated region (UTR) ensures efficient translation during stress, when eIF2 $(\alpha \mathrm{P})$ levels are high (Palam et al. 2011). However, constructs lacking uORFs are translated under stress conditions; thus transcriptional control alone should suffice to switch these genes on during stress. Alternatively, the combined transcription and translation control affords both activation during stress by a transcriptional mechanism and rapid inactivation of translation with the decline in $\operatorname{eIF} 2(\alpha \mathrm{P})$ levels once the stress has been resolved.

\section{HOW WIDESPREAD IS UORF- AND eIF2 $(\alpha \mathrm{P})$-MEDIATED TRANSLATIONAL CONTROL?}

It remains unclear how widespread $\operatorname{eIF}(\alpha \mathrm{P})$ mediated uORF control of translation is. Recent genome-wide studies concluded that approximately half of human and mouse genes possess one or more uORFs (Calvo et al. 2009); this compares with $\sim 13 \%$ of yeast genes (Lawless et al. 2009). The yeast study revealed that mRNAs that are translationally up-regulated by stresses that cause increased eIF2 $(\alpha \mathrm{P})$ have significantly longer $5^{\prime}$ UTRs with more uORFs than the reference pool of mRNAs. A separate study, using a new high-throughput sequencing method to determine ribosome-protected RNA fragments or "ribosome footprints" on total yeast mRNA, observed a significant increase in ribosome footprints in $5^{\prime}$ UTRs following induction of eIF2 $(\alpha \mathrm{P})$ by amino acid deprivation (Ingolia et al. 2009). In many cases translation at the novel uORFs was found to initiate at non-AUG codons, suggesting that start codon recognition is altered by a stress-induced increase in eIF2 phosphorylation. Are non-AUG-initiating ribosomes important for translational control? This is not yet clear, but a recent study experimentally examined the two newly discovered non-AUG uORFs (termed nAuORFs) identified by Ingolia and colleagues in the GCN4 leader sequence (Zhang and Hinnebusch 2011). They found that one of the GCN4 nAuORFs was translated but not at a level sufficient to influence the wellestablished uORF control mechanism. Thus, nAuORFs are not important for GCN4 translation; their significance across the transcriptome remains unclear and requires further experimentation. Similar genome-wide studies will be required to establish whether these findings in yeast apply to the mammalian UPR.

\section{SEPARATING THE EFFECTS OF EIF $2 \alpha$ PHOSPHORYLATION ON BULK PROTEIN SYNTHESIS FROM ITS EFFECTS ON GENE EXPRESSION}

Gene knockout in mice and rare human mutations in EIF2AK3, the gene encoding PERK, point to the critical role of ER stress-induced 
eIF2 $\alpha$ phosphorylation in the survival and wellbeing of secretory cells (Harding et al. 2001; Zhang et al. 2002; Julier and Nicolino 2010). These observations are most readily explained by the critical role of eIF $2(\alpha \mathrm{P})$ in attenuating the flux of proteins into the ER lumen. Secretory cells that are subject to powerful physiologically driven increase in rates of secretory protein synthesis are most heavily dependent on the moderating influence of eIF $2 \alpha$ phosphorylation on unfolded protein stress (Trusina et al. 2008). This simple explanation, which emphasizes the control of bulk protein synthesis, fits nicely with the observed engorgement of the ER in secretory cells of PERK-knockout animals (Harding et al. 2001; Zhang et al. 2002).

Careful analysis of insulin-producing $\beta$ cells suggests that PERK signaling affects aspects of ER function that go beyond protein folding. PERK-knockout cells exhibit defects in vesicular transport from the ER to Golgi and in the degradation of unfolded ER proteins (Gupta et al. 2010). These defects could well be explained by enhanced load of unfolded proteins in the ER of PERK-deficient cells. However, as eIF2 $\alpha$ phosphorylation is also coupled to changes in gene transcription (mediated by ATF4 and ATF5, as noted above), it is difficult to exclude a role for altered developmental programs in the outcome of PERK deficiency. Resolution of this problem awaits the emergence of tools to inactivate PERK-dependent gene expression programs without affecting bulk protein synthesis.

\section{THE BIPHASIC RELATIONSHIP BETWEEN EIF2 $\alpha$ PHOSPHORYLATION AND FITNESS OF STRESSED CELLS}

The benefits of linking ER stress to increased levels of eIF $2 \alpha$ phosphorylation are made plain by the phenotype of PERK deficiency. However, it stands to reason that excess levels of phosphorylated eIF $2 \alpha$ would interfere with the essential process of protein synthesis. This conjecture is strongly supported by the phenotype of loss-of-function mutations affecting the phosphatases that dephosphorylate eIF $2 \alpha$.

Two phosphatase complexes are known to dephosphorylate eIF $2 \alpha$. They consist of a single regulatory subunit, PPP1R15A (also known as GADD34 or MyD116; see above) or PPP1R15B (also known as CReP), and a common catalytic subunit, protein phosphatase 1 (PP1), which in mammals have four different isoforms encoded by three different genes. PPP1R15A/GADD34 is encoded by an inducible gene, whose expression is under the control of ATF4 and is therefore responsive to levels of phosphorylated $\operatorname{eIF} 2 \alpha$, and whose mRNA is subject to translational regulation, as noted above. Thus, PPP1R15A participates in a transcriptionally mediated negative-feedback loop that controls levels of phosphorylated eIF2 $\alpha$ (Novoa et al. 2001, 2003; Brush et al. 2003). PPP1R15B (CReP) is encoded by a constitutively active gene and contributes to basal levels of eIF2 $(\alpha \mathrm{P})$-directed phosphatase activity (Jousse et al. 2003).

Gene knockout of these two PPP1R15 isoforms is informative in regard to the physiological role of eIF2 $(\alpha \mathrm{P})$ dephosphorylation. PPP1$\mathrm{R} 15 \mathrm{~A}$ knockout is well tolerated, with mice exhibiting an essentially normal phenotype. In fact, the knockout mice are resistant to some injuries induced by progressive ER stress (Marciniak et al. 2004). However, in response to injuries that result in rapid and sustained activation of PERK, such as the application of the toxin thapsigargin, the PPP1R15A-deficient cells show decreased fitness, which correlates with impaired recovery from PERK-mediated translation repression (Novoa et al. 2003). A role for unsustainably high levels of eIF2 $(\alpha \mathrm{P})$ in death of severely ER-stressed cells was more recently suggested by the temporal profile of the activity of the known UPR transducers in response to severe ER stress; sustained and overexuberant PERK activity correlated with cell death (Lin et al. 2007; Calvo et al. 2009).

Inactivation of the constitutive PPP1R15B subunit was also informative. Early development was normal in knockout mice, but anemia developed late in gestation and the mice were stillborn. Compounding the PPP1R15B knockout with loss of PPP1R15A dramatically accelerated the embryonic lethality to the preimplantation stage. Importantly, the severely compromising compound mutant phenotype could be rescued completely by a mutation rendering 
eIF2 $\alpha$ unphosphorylatable (eIF2 $\alpha$ S51A) (Harding et al.2009). These observations confirm the nonredundant role of the two PPP1R15 regulatory subunits in eIF $2(\alpha \mathrm{P})$ dephosphorylation and highlight the consequences of excessive levels of phosphorylated eIF $2 \alpha$.

Recent progress in chemical biology has provided further support for the biphasic relationship between levels of phosphorylated eIF $2 \alpha$ and fitness and has suggested a way to manipulate eIF2 $(\alpha \mathrm{P})$ dephosphorylation for the benefit of stressed cells. The small molecule guanabenz, originally developed as an antihypertensive drug, was found to selectively interfere with the formation of the complex between PPP1R15A and the catalytic subunit, thus selectively inhibiting the PPP1R15A-mediated stress-inducible dephosphorylation of eIF2 $(\alpha \mathrm{P})$ while sparing the constitutive activity of PPP1R15B (Fig. 3) (Tsaytler et al. 2011). In keeping with this mechanism of action, guanabenz protected wild-type ER-stressed cells from death and had no effect on cells lacking PPP1R15A. But its application resulted in rapid loss of viability of cells lacking PPP1R15B, in which guanabenz led to unsustainable increases in levels of phosphorylated eIF $2 \alpha$.

The selectivity of guanabenz for PPP1R15A over PPP1R15B is in contrast to salubrinal, an inhibitor of eIF2 $(\alpha \mathrm{P})$ dephosphorylation that targets both phosphatase complexes (Boyce et al. 2005). These differences may explain the ability of guanabenz to protect cells against ER stress over a broad range of concentrations, compared with the narrower window of utility of salubrinal. Unfortunately, guanabenz is far less active against the PPP1R15A complex than it is against $\alpha 1$-adrenergic receptors (the basis of its utility as an antihypertensive drug). Thus, in vivo toxicity limits the prospects of testing its ability to protect against physiologically relevant models of ER stress.

\section{TRANSLATIONAL PAUSING ENABLES COLOCALIZATION OF THE XBP1 mRNA AND IRE1'S EFFECTOR DOMAIN}

IRE1-mediated cleavage of the mRNA encoding the transcription factor XBP1 and the subsequent splicing of the resulting $5^{\prime}$ and $3^{\prime}$ mRNA fragments (with elimination of the intron) is the key effector event in the most ancient arm of the UPR. The (unconventionally) spliced $X B P 1$ mRNA encodes a potent transcription factor that activates UPR target genes. ER stress is coupled to IRE1 activation by IRE1's self-directed protein kinase, thereby generating autophosphorylated IRE1 that acquires endoribonucleolytic activity (Bernales et al. 2006).

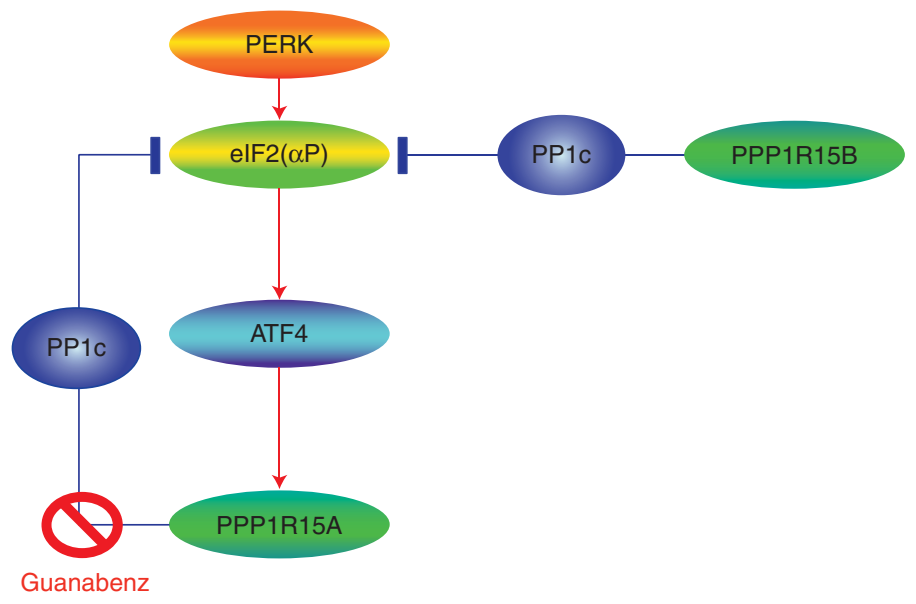

Figure 3. eIF2 $(\alpha \mathrm{P})$ dephosphorylation. eIF2 $(\alpha \mathrm{P})$ dephosphorylation is mediated by two phosphatase complexes: one with the constitutive regulatory subunit PPP1R15B and the other with the stress-inducible subunit PPP1R15A. The latter complex is subject to selective inhibition by guanabenz, whose application provides a measure of protection against the lethal consequences of ER stress. 
In addition to the essential activation of IRE1 as an enzyme, recent work has pointed to an important role for targeted mRNA localization in IRE1-mediated XBP1 mRNA cleavage. In mammals, localization of the XBP1 mRNA has proven to depend on a novel mechanism of translational regulation.

IRE1 is an ER-localized transmembrane protein. Efficient cleavage of the XBP1 mRNA by IRE1's effector endoribonuclease domain requires the colocalization of the two to the cytosolic face of the ER membrane. This, it turn, depends on the presence of a hydrophobic protein sequence at the carboxyl terminus encoded by the unspliced (inactive) XBP1 mRNA. Interaction of the hydrophobic sequence (called hydrophobic region 2, or HR2) with the ER membrane is believed to recruit the XBP1 nascent chain and associated ribosome and unspliced mRNA to the cytosolic face of the ER membrane, in proximity to IRE1's effector domain (Fig. 4). The IRE1-mediated unconventional splicing event alters the $X B P 1$ coding sequence, eliminating the hydrophobic sequence. This untethers the ribosome-nascent chain complex encoding the spliced form of XBP1 from the ER (Yanagitani et al. 2009).
This proposed mechanism nicely explains the dependence of XBP1 mRNA localization on the hydrophobic segment encoded by the unspliced mRNA. However, the HR2 segment is encoded at the extreme $3^{\prime}$ end of the coding sequence, 53 residues from the stop codon. Assuming normal elongation rates of 3-8 residues/sec, the dwell time of this hydrophobic sequence in the ribosome-nascent chain complex is expected to be very short, significantly limiting its utility as a tether. To counteract this limitation, the unspliced XBP1 coding sequence evolved features that specify translational pausing. The pause is conveniently located very close to the stop codon, providing sufficient length for the preceding HR2 to make its way out of the ribosomal tunnel and interact with the ER membrane (Fig. 4) (Yanagitani et al. 2011). The molecular details of the pause have features in common with pausing in bacterial systems, in that it depends on the side chains of residues engaged in the ribosomal tunnel and may exploit the poor nucleophilicity of proline's secondary amine to position such a residue at the ribosome "A" site in the stalled complex (Nakatogawa and Ito 2002). Given the very high precision by which ribosome pauses can be mapped

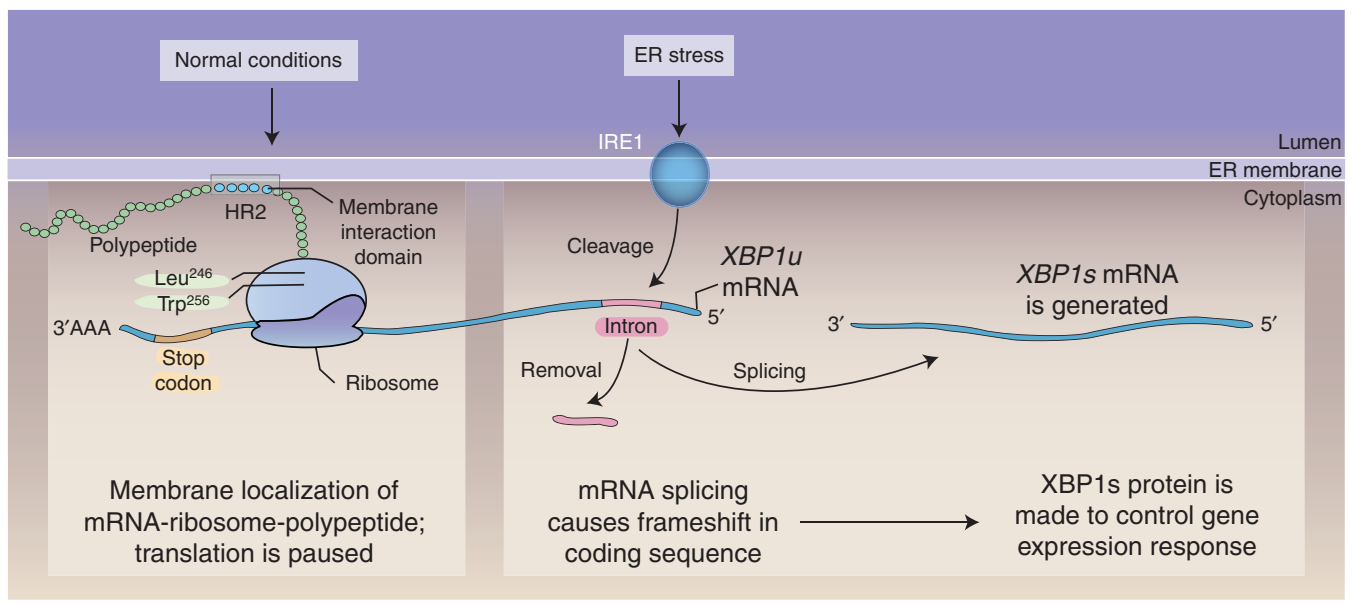

Figure 4. Translational pausing and IRE1-mediated splicing of XBP1. To be poised for rapid splicing in response to the accumulation of unfolded proteins in the ER, unspliced XBP1 $u$ mRNA is tethered to the ER membrane by the paused ribosome-nascent chain complex. Pausing requires interactions of Leu246 and Trp256 in the nascent chain with the ribosome. The pause stabilizes the complex, favoring cleavage of XBP1u by IRE1. This causes a frameshift in the coding sequence of the spliced XBP1s mRNA, which precludes translation of Leu246 and Trp256 and relieves the pause. (Reprinted, with permission, from Ron and Ito 2011.) 
on mRNAs in vivo (see above), it will be interesting to see if this prediction is borne out.

\section{IRE1'S PROMISCUOUS RNase ACTIVITY AND PROTEIN-FOLDING HOMEOSTASIS IN THE ER}

In addition to its highly sequence-specific RNase activity, directed toward two sites in the XBP1 mRNA, observations first made in cultured insect cells point to an additional role for IRE1 in promiscuous degradation of membrane-bound mRNAs. It was noted that certain mRNAs, whose levels decreased in wild-type cells exposed to agents that promote ER stress, were spared this fate in IRE1-knockdown ERstressed cells. Interestingly, this sparing effect was not observed in XBP1-knockdown cells, suggesting that decline in the levels of these mRNAs is not mediated by IRE1-dependent transcriptional programs. Furthermore, inhibiting the XRN1 and SKI2 exoribonucleases that processively degrade uncapped and deadenylated mRNAs led to appearance of fragments of the mRNAs targeted by this process. Importantly, such mRNA fragments were not observed in cells lacking IRE1. Therefore the process was termed regulated IRE1-dependent degradation (or RIDD) (Hollien and Weissman 2006).

Evidence has since mounted that RIDD is not an oddity confined to cultured insect cells but also occurs in other (mammalian) animal cells, but interestingly not in budding yeast (Hollien et al. 2009). The physiological role of RIDD is far from clear. It occurs relatively late in the course of the ER stress response and only in response to relatively high levels of ER stress. An important clue is provided by the observation that RIDD targets mRNAs encoding secreted and transmembrane ER client proteins. Thus, from the perspective of its effect on unfolded protein load in the ER, RIDD is allied to PERKmediated translational repression, the latter as a rapid response to imbalance in the ER lumen and the former as a backup mechanism of longer latency. In addition to its predicted effects on the bulk flow of proteins into the ER, RIDD may also play a role in reprogramming the translational apparatus of the ER membrane.
By purging the cells of preexisting secreted protein, it favors the expression of a new repertoire of transcriptionally induced UPR target genes.

The two processes noted above are predicted to benefit the stressed cells, by lowering ER client protein load and promoting organellar adaptation to the stress. But there is also evidence that RIDD may play a role in the demise of ERstressed cells. This is supported by the observation that hyperactivity of an IRE1 enzyme whose kinase domain has been modified to be less efficient in coupling ER stress to RIDD is better tolerated than hyperactivity of the wild-type, fully RIDD-proficient enzyme (Han et al. 2009).

It is unclear how RIDD would be coupled to cell death, but this link may not be entirely without precedent. The endoribonuclease most similar in sequence to IRE1 is RNase L, an interferon-inducible, promiscuous RNase whose fury is unleashed in virally infected cells as an antiviral strategy to compromise their function and viability (Bork and Sander 1993). The ancestral IRE1 may have been a sequence-specific RNase (and has remained so in budding yeast). In animal cells the enzyme evolved some promiscuous RNase activity. The intensity at which this RNase is activated contributes to a life/death decision in ER-stressed cells by controlling client protein load or effecting lethal levels of RNA degradation. A gene duplication yielded RNase $\mathrm{L}$, whose function is directed toward the latter, destructive goal. This parallels the situation in regards to eIF $2 \alpha$ phosphorylation. Simpler organisms possess eIF $2 \alpha$ kinases that promote fitness of the individual cell (e.g., PERK to protect against ER stress). But more complex organisms evolved an eIF $2 \alpha$ kinase, PKR, that is activated by viral infection and whose activity promotes fitness of the organism at the expense of the individual cells in which PKR is activated.

\section{CONCLUDING REMARKS}

The endoplasmic reticulum stress response exploits diverse mechanisms for translational regulation. These promote protein-folding homeostasis in the ER lumen of individual cells and tissue homeostasis at the level of the whole organism. Thus, translational regulation is an 
Translational Regulation in the UPR

important facet of several nodes that influence important life-and-death decisions in ERstressed cells and beyond.

\section{ACKNOWLEDGMENTS}

D.R. is a Principal Research Fellow of the Wellcome Trust. Work in G.D.P.'s laboratory is funded by grants from the Biotechnology and Biological Sciences Research Council and the European Union (Framework Program 7).

\section{REFERENCES}

Bernales S, Papa FR, Walter P. 2006. Intracellular signaling by the unfolded protein response. Annu Rev Cell Dev Biol 22: $487-508$.

Bork P, Sander C. 1993. A hybrid protein kinase-RNase in an interferon-induced pathway? FEBS Lett 334: 149-152.

Boyce M, Bryant KF, Jousse C, Long K, Harding HP, Scheuner D, Kaufman RJ, Ma D, Coen D, Ron D, et al. 2005. A selective inhibitor of eIF2 $\alpha$ dephosphorylation protects cells from ER stress. Science 307: 935-939.

Brush MH, Weiser DC, Shenolikar S. 2003. Growth arrest and DNA damage-inducible protein GADD34 targets protein phosphatase $1 \alpha$ to the endoplasmic reticulum and promotes dephosphorylation of the $\alpha$ subunit of eukaryotic translation initiation factor 2. Mol Cell Biol 23: $1292-1303$.

Calfon M, Zeng H, Urano F, Till JH, Hubbard SR, Harding HP, Clark SG, Ron D. 2002. IRE1 couples endoplasmic reticulum load to secretory capacity by processing the XBP-1 mRNA. Nature 415: 92-96.

Calvo SE, Pagliarini DJ, Mootha VK. 2009. Upstream open reading frames cause widespread reduction of protein expression and are polymorphic among humans. Proc Natl Acad Sci 106: 7507-7512.

Cox JS, Walter P. 1996. A novel mechanism for regulating activity of a transcription factor that controls the unfolded protein response. Cell 87: 391-404.

Cox JS, Shamu CE, Walter P. 1993. Transcriptional induction of genes encoding endoplasmic reticulum resident proteins requires a transmembrane protein kinase. Cell 73: 1197-1206.

Das S, Ghosh R, Maitra U. 2001. Eukaryotic translation initiation factor 5 functions as a GTPase-activating protein. J Biol Chem 276: 6720-6726.

Elsby R, Heiber JF, Reid P, Kimball SR, Pavitt GD, Barber GN. 2011. The $\alpha$ subunit of eukaryotic initiation factor 2B (eIF2B) is required for eIF2-mediated translational suppression of vesicular stomatitis virus. J Virol 85: 9716-9725.

Fogli A, Rodriguez D, Eymard-Pierre E, Bouhour F, Labauge P, Meaney BF, Zeesman S, Kaneski CR, Schiffmann R, Boespflug-Tanguy O. 2003. Ovarian failure related to eukaryotic initiation factor 2B mutations. Am J Hum Genet 72: $1544-1550$.
Geva M, Cabilly Y, Assaf Y, Mindroul N, Marom L, Raini G, Pinchasi D, Elroy-Stein O. 2010. A mouse model for eukaryotic translation initiation factor 2B-leucodystrophy reveals abnormal development of brain white matter. Brain 133: 2448-2461.

Gupta S, McGrath B, Cavener DR. 2010. PERK (EIF2AK3) regulates proinsulin trafficking and quality control in the secretory pathway. Diabetes 59: 1937-1947.

Han D, Lerner AG, Vande Walle L, Upton JP, Xu W, Hagen A, Backes BJ, Oakes SA, Papa FR. 2009. IRE1 $\alpha$ kinase activation modes control alternate endoribonuclease outputs to determine divergent cell fates. Cell 138: 562-575.

Harding HP, Zhang Y, Bertolotti A, Zeng H, Ron D. 2000. Perk is essential for translational regulation and cell survival during the unfolded protein response. Mol Cell 5: 897-904.

Harding H, Zeng H, Zhang Y, Jungreis R, Chung P, Plesken H, Sabatini D, Ron D. 2001. Diabetes mellitus and exocrine pancreatic dysfunction in Perk ${ }^{-/-}$mice reveals a role for translational control in survival of secretory cells. Mol Cell 7: 1153-1163.

Harding H, Zhang Y, Zeng H, Novoa I, Lu P, Calfon M, Sadri N, Yun C, Popko B, Paules R, et al. 2003. An integrated stress response regulates amino acid metabolism and resistance to oxidative stress. Mol Cell 11: 619-633.

Harding HP, Zhang Y, Scheuner D, Chen JJ, Kaufman RJ, Ron D. 2009. Ppp1r15 gene knockout reveals an essential role for translation initiation factor 2 alpha (eIF2 $\alpha)$ dephosphorylation in mammalian development. Proc Natl Acad Sci 106: 1832-1837.

Hollien J, Weissman JS. 2006. Decay of endoplasmic reticulum-localized mRNAs during the unfolded protein response. Science 313: 104-107.

Hollien J, Lin JH, Li H, Stevens N, Walter P, Weissman JS. 2009. Regulated Ire1-dependent decay of messenger RNAs in mammalian cells. J Cell Biol 186: 323-331.

Horzinski L, Huyghe A, Cardoso MC, Gonthier C, Ouchchane L, Schiffmann R, Blanc P, Boespflug-Tanguy O, Fogli A. 2009. Eukaryotic initiation factor 2B (eIF2B) GEF activity as a diagnostic tool for EIF2B-related disorders. PLoS ONE 4: e8318.

Horzinski L, Kantor L, Huyghe A, Schiffmann R, ElroyStein O, Boespflug-Tanguy O, Fogli A. 2010. Evaluation of the endoplasmic reticulum-stress response in eIF2Bmutated lymphocytes and lymphoblasts from $\mathrm{CACH} /$ VWM patients. BMC Neurol 10: 94.

Ingolia NT, Ghaemmaghami S, Newman JR, Weissman JS. 2009. Genome-wide analysis in vivo of translation with nucleotide resolution using ribosome profiling. Science 324: $218-223$.

Itoh N, Okamoto H. 1980. Translational control of proinsulin synthesis by glucose. Nature 283: 100-102.

Jackson RJ, Hellen CU, Pestova TV. 2010. The mechanism of eukaryotic translation initiation and principles of its regulation. Nat Rev Mol Cell Biol 11: 113-127.

Jennings MD, Pavitt GD. 2010. eIF5 has GDI activity necessary for translational control by eIF2 phosphorylation. Nature 465: 378-381.

Jousse C, Oyadomari S, Novoa I, Lu PD, Zhang Y, Harding HP, Ron D. 2003. Inhibition of a constitutive translation 
initiation factor $2 \alpha$ phosphatase, CReP, promotes survival of stressed cells. J Cell Biol 163: 767-775.

Julier C, Nicolino M. 2010. Wolcott-Rallison syndrome. Orphanet J Rare Dis 5: 29.

Kantor L, Harding HP, Ron D, Schiffmann R, Kaneski CR, Kimball SR, Elroy-Stein O. 2005. Heightened stress response in primary fibroblasts expressing mutant eIF2B genes from $\mathrm{CACH} / \mathrm{VWM}$ leukodystrophy patients. Hum Genet 118: 99-106.

Kantor L, Pinchasi D, Mintz M, Hathout Y, Vanderver A, Elroy-Stein O. 2008. A point mutation in translation initiation factor 2B leads to a continuous hyper stress state in oligodendroglial-derived cells. PLoS ONE 3: e3783.

Kimball SR, Fabian JR, Pavitt GD, Hinnebusch AG, Jefferson LS. 1998. Regulation of guanine nucleotide exchange through phosphorylation of eukaryotic initiation factor eIF2 $\alpha$. Role of the $\alpha$ - and $\delta$-subunits of eIF2b. J Biol Chem 273: 12841-12845.

Krishnamoorthy T, Pavitt GD, Zhang F, Dever TE, Hinnebusch AG. 2001. Tight binding of the phosphorylated $\alpha$ subunit of initiation factor 2 (eIF2 $\alpha$ ) to the regulatory subunits of guanine nucleotide exchange factor eIF2B is required for inhibition of translation initiation. Mol Cell Biol 21: 5018-5030.

Lawless C, Pearson RD, Selley JN, Smirnova JB, Grant CM, Ashe MP, Pavitt GD, Hubbard SJ. 2009. Upstream sequence elements direct post-transcriptional regulation of gene expression under stress conditions in yeast. BMC Genomics 10: 7.

Lee YY, Cevallos RC, Jan E. 2009. An upstream open reading frame regulates translation of GADD34 during cellular stresses that induce eIF2 $\alpha$ phosphorylation. J Biol Chem 284: 6661-6673.

Lin JH, Li H, Yasumura D, Cohen HR, Zhang C, Panning B, Shokat KM, Lavail MM, Walter P. 2007. IRE1 signaling affects cell fate during the unfolded protein response. Science 318: 944-949.

Lu PD, Harding HP, Ron D. 2004. Translation reinitiation at alternative open reading frames regulates gene expression in an integrated stress response. J Cell Biol 167: 27-33.

Marciniak SJ, Yun CY, Oyadomari S, Novoa I, Zhang Y, Jungreis R, Nagata K, Harding HP, Ron D. 2004. CHOP induces death by promoting protein synthesis and oxidation in the stressed endoplasmic reticulum. Genes Dev 18: 3066-3077.

Martin-Marcos P, Cheung YN, Hinnebusch AG. 2011. Functional elements in initiation factors $1,1 \mathrm{~A}$ and $2 \beta$ discriminate against poor AUG context and non-AUG start codons. Mol Cell Biol 31: 4814-4831.

Mori K, Ma W, Gething MJ, Sambrook J. 1993. A transmembrane protein with a cdc2 ${ }^{+} / \mathrm{CDC} 28$-related kinase activity is required for signaling from the ER to the nucleus. Cell 74: 743-756.

Nakatogawa H, Ito K. 2002. The ribosomal exit tunnel functions as a discriminating gate. Cell 108: 629-636.

Nika J, Yang W, Pavitt GD, Hinnebusch AG, Hannig EM. 2000. Purification and kinetic analysis of eIF2B from Saccharomyces cerevisiae. J Biol Chem 275: 26011-26017.

Novoa I, Zeng H, Harding H, Ron D. 2001. Feedback inhibition of the unfolded protein response by GADD34- mediated dephosphorylation of eIF2 $\alpha . J$ Cell Biol 153: 1011-1022.

Novoa I, Zhang Y, Zeng H, Jungreis R, Harding HP, Ron D. 2003. Stress-induced gene expression requires programmed recovery from translational repression. $E M B O$ J 22: 1180-1187.

Palam LR, Baird TD, Wek RC. 2011. Phosphorylation of eIF2 facilitates ribosomal bypass of an inhibitory upstream ORF to enhance CHOP translation. J Biol Chem 286: 10939-10949.

Paulin FE, Campbell LE, O’Brien K, Loughlin J, Proud CG. 2001. Eukaryotic translation initiation factor 5 (eIF5) acts as a classical GTPase-activator protein. Curr Biol 11: 55-59.

Pavitt GD, Proud CG. 2009. Protein synthesis and its control in neuronal cells with a focus on vanishing white matter disease. Biochem Soc Trans 37: 1298-1310.

Pavitt GD, Yang W, Hinnebusch AG. 1997. Homologous segments in three subunits of the guanine nucleotide exchange factor eIF2B mediate translational regulation by phosphorylation of eIF2. Mol Cell Biol 17: 1298-1313.

Pavitt GD, Ramaiah KV, Kimball SR, Hinnebusch AG. 1998. eIF2 independently binds two distinct eIF2B subcomplexes that catalyze and regulate guanine-nucleotide exchange. Genes Dev 12: 514-526.

Pisarev AV, Kolupaeva VG, Pisareva VP, Merrick WC, Hellen CU, Pestova TV. 2006. Specific functional interactions of nucleotides at key ${ }^{-} 3$ and ${ }^{+} 4$ positions flanking the initiation codon with components of the mammalian 485 translation initiation complex. Genes Dev 20: 624-636.

Poyry TA, Kaminski A, Jackson RJ. 2004. What determines whether mammalian ribosomes resume scanning after translation of a short upstream open reading frame? Genes Dev 18: 62-75.

Ron D, Harding H. 2007. eIF2 $\alpha$ phosphorylation in cellular stress responses and disease. In Translational control (ed. Sonenberg N, et al.), pp. 345-368. Cold Spring Harbor Laboratory Press, Cold Spring Harbor, NY.

Ron D, Ito K. 2011. Cell biology: A translational pause to localize. Science 331: 543-544.

Ron D, Walter P. 2007. Signal integration in the endoplasmic reticulum unfolded protein response. Nat Rev Mol Cell Biol 8: 519-529.

Rowlands AG, Panniers R, Henshaw EC. 1988. The catalytic mechanism of guanine nucleotide exchange factor action and competitive inhibition by phosphorylated eukaryotic initiation factor 2. J Biol Chem 263: 5526-5533.

Singh CR, Lee B, Udagawa T, Mohammad-Qureshi SS, Yamamoto Y, Pavitt GD, Asano K. 2006. An eIF5/eIF2 complex antagonizes guanine nucleotide exchange by eIF2B during translation initiation. EMBO J 25: 4537-4546.

Trusina A, Papa FR, Tang C. 2008. Rationalizing translation attenuation in the network architecture of the unfolded protein response. Proc Natl Acad Sci 105: 20280-20285.

Tsaytler P, Harding HP, Ron D, Bertolotti A. 2011. Selective inhibition of a regulatory subunit of protein phosphatase 1 restores proteostasis. Science 332: 91-94.

van der Knaap MS, van Berkel CG, Herms J, van Coster R, Baethmann M, Naidu S, Boltshauser E, Willemsen MA, Plecko B, Hoffmann GF, et al. 2003. eIF2B-related 
Translational Regulation in the UPR

disorders: Antenatal onset and involvement of multiple organs. Am J Hum Genet 73: 1199-1207.

van Kollenburg B, van Dijk J, Garbern J, Thomas AA, Scheper GC, Powers JM, van der Knaap MS. 2006. Glia-specific activation of all pathways of the unfolded protein response in vanishing white matter disease. $J$ Neuropathol Exp Neurol 65: 707-715.

Vattem KM, Wek RC. 2004. Reinitiation involving upstream ORFs regulates ATF4 mRNA translation in mammalian cells. Proc Natl Acad Sci 101: 11269-11274.

Yanagitani K, Imagawa Y, Iwawaki T, Hosoda A, Saito M, Kimata Y, Kohno K. 2009. Cotranslational targeting of XBP1 protein to the membrane promotes cytoplasmic splicing of its own mRNA. Mol Cell 34: 191-200.

Yanagitani K, Kimata Y, Kadokura H, Kohno K. 2011. Translational pausing ensures membrane targeting and cytoplasmic splicing of XBP1 $u$ mRNA. Science 331: 586-589.
Yoshida H, Matsui T, Yamamoto A, Okada T, Mori K. 2001. XBP1 mRNA is induced by ATF6 and spliced by IRE1 in response to ER stress to produce a highly active transcription factor. Cell 107: 881-891.

Zhang F, Hinnebusch AG. 2011. An upstream ORF with non-AUG start codon is translated in vivo but dispensable for translational control of GCN4 mRNA. Nucleic Acids Res 39: 3128-3140.

Zhang P, McGrath B, Li S, Frank A, Zambito F, Reinert J, Gannon M, Ma K, McNaughton K, Cavener DR. 2002. The PERK eukaryotic initiation factor $2 \alpha$ kinase is required for the development of the skeletal system, postnatal growth, and the function and viability of the pancreas. Mol Cell Biol 22: 3864-3874.

Zhou D, Palam LR, Jiang L, Narasimhan J, Staschke KA, Wek RC. 2008. Phosphorylation of eIF2 directs ATF5 translational control in response to diverse stress conditions. $J$ Biol Chem 283: 7064-7073. 


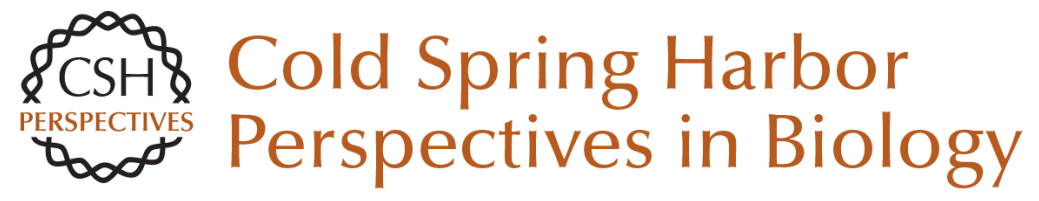

\title{
New Insights into Translational Regulation in the Endoplasmic Reticulum Unfolded Protein Response
}

\author{
Graham D. Pavitt and David Ron
}

Cold Spring Harb Perspect Biol 2012; doi: 10.1101/cshperspect.a012278 originally published online April 25, 2012

\section{Subject Collection Protein Synthesis and Translational Control}

Tinkering with Translation: Protein Synthesis in

Virus-Infected Cells

Derek Walsh, Michael B. Mathews and lan Mohr

Translational Control in Cancer Etiology

Davide Ruggero

\section{A Molecular Link between miRISCs and Deadenylases Provides New Insight into the Mechanism of Gene Silencing by MicroRNAs Joerg E. Braun, Eric Huntzinger and Elisa Izaurralde}

Imaging Translation in Single Cells Using Fluorescent Microscopy Jeffrey A. Chao, Young J. Yoon and Robert $H$. Singer

mRNA Localization and Translational Control in Drosophila Oogenesis Paul Lasko

P-Bodies and Stress Granules: Possible Roles in the Control of Translation and mRNA Degradation Carolyn J. Decker and Roy Parker

Protein Secretion and the Endoplasmic Reticulum Adam M. Benham
Toward a Genome-Wide Landscape of

Translational Control

Ola Larsson, Bin Tian and Nahum Sonenberg

The Current Status of Vertebrate Cellular mRNA IRESS

Richard J. Jackson

Principles of Translational Control: An Overview John W.B. Hershey, Nahum Sonenberg and Michael B. Mathews

Regulation of mRNA Translation by Signaling Pathways

Philippe P. Roux and Ivan Topisirovic

The Mechanism of Eukaryotic Translation Initiation: New Insights and Challenges Alan G. Hinnebusch and Jon R. Lorsch

Single-Molecule Analysis of Translational Dynamics Alexey Petrov, Jin Chen, Seán O'Leary, et al.

Cytoplasmic RNA-Binding Proteins and the Control of Complex Brain Function Jennifer C. Darnell and Joel D. Richter

For additional articles in this collection, see http://cshperspectives.cshlp.org/cgi/collection/

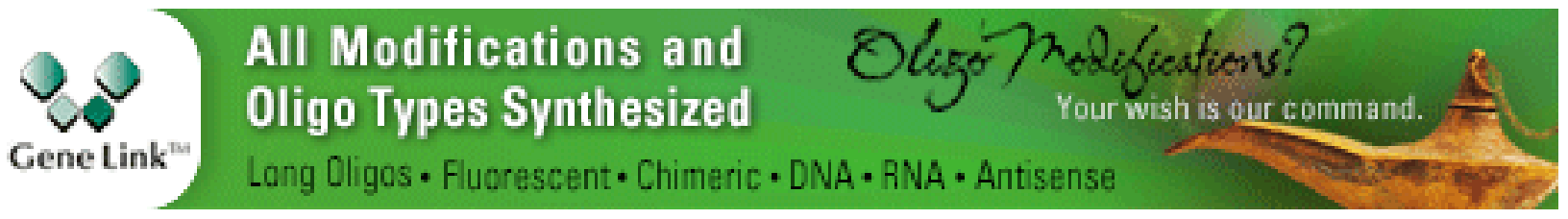




\section{From Cis-Regulatory Elements to Complex RNPs and Back}

Fátima Gebauer, Thomas Preiss and Matthias W. Hentze
The Elongation, Termination, and Recycling Phases of Translation in Eukaryotes

Thomas E. Dever and Rachel Green

For additional articles in this collection, see http://cshperspectives.cshlp.org/cgi/collection/

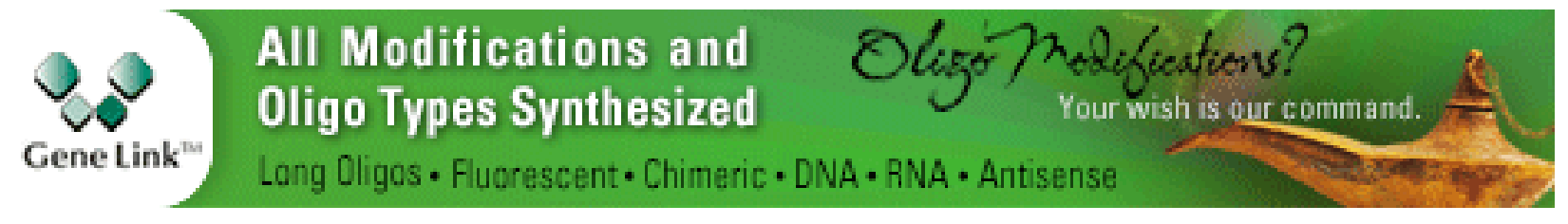

Copyright @ 2012 Cold Spring Harbor Laboratory Press; all rights reserved 